Théologiques

Théologiques

\title{
Religion populaire et superstition au Moyen Âge
}

\section{Micheline Laliberté}

Volume 8, numéro 1, printemps 2000

La superstition

URI : https://id.erudit.org/iderudit/005012ar

DOI : https://doi.org/10.7202/005012ar

Aller au sommaire du numéro

\section{Éditeur(s)}

Faculté de théologie de l'Université de Montréal

\section{ISSN}

1188-7109 (imprimé)

1492-1413 (numérique)

Découvrir la revue

\section{Citer cet article}

Laliberté, M. (2000). Religion populaire et superstition au Moyen Âge.

Théologiques, 8(1), 19-36. https://doi.org/10.7202/005012ar

\section{Résumé de l'article}

La superstition, toujours difficile à cerner, est une forme de religionpopulaire plus ou moins reçue ou tolérée. Durant la longue période duMoyen Âge, elle prend différentes figures dont on ne peut rendre comptefacilement. Le propos de cet article est de faire ressortir, à partir de travauxrécents, quelques traits fondamentaux de superstitions au Moyen Âge entenant compte, entre autres, de la perception de certains auteurs de cettepériode. À la suite de cela, nous pourrons mieux saisir quelques unes desvaleurs accolées à ce terme de superstition, valeurs qui ont traversé lessiècles et qui se sont répercutées jusque dans les travaux de chercheurs de ladeuxième moitié du XXe siècle. 


\section{Religion populaire et superstition au Moyen Âge}

Micheline LALIBERTÉ

Département de sciences humaines

Université Sainte-Anne

Nouvelle-Écosse

Avant d'aborder les relations qui se tissent entre le couple religion populaire et superstition au cours du Moyen Âge, il faut d'abord situer rapidement la notion de religion populaire dans l'historiographie des dernières années, ceci afin de mettre en valeur différents aspects sous-jacents à cette problématique. ${ }^{1}$

\section{En quête de religion populaire}

C’est à partir du milieu des années 1960 que la notion de religion populaire commence à attirer de plus en plus l'attention des chercheurs en France et en Italie notamment. Parmi les facteurs pouvant expliquer cet intérêt, mentionnons l'impact de Vatican II et des réformes liturgiques proposées par lui, les orientations développées par les recherches en sociologie religieuse, les discussions en historiographie au sujet de la déchristianisation, et enfin l'influence de l'école des Annales et de la "nouvelle histoire ». Un des apports principaux de ces différents facteurs, et aussi leur point en commun, consistait à délaisser l'histoire de la structure ecclésiastique pour privilégier

1. Indiquons qu'à l'origine de cette réflexion, il y eut la motivation d'explorer les mentalités à la fin du Moyen Âge et que, pour ce faire, la thématique de la religion populaire s'est imposée rapidement comme un filon particulièrement fertile. Comme complément aux informations présentées dans cet article, voir notre thèse de doctorat présentée à l'Université de Montréal en juin 1998 : La religion populaire en France à la fin du Moyen Âge. Fécondité et limites d'une catégorie historiographique, 402p. 
l'étude du peuple. À travers la diversité des discours et des tendances, chacun de ces facteurs a contribué à renouveler, ou du moins à poser différemment, la problématique liée à la dialectique entre le christianisme officiel et la religion populaire.

Au cours des années 1970, les discussions autour de la notion de religion populaire suscitent de nombreux colloques et publications tant en Europe qu'au Québec. ${ }^{2}$ Spécifions que ces recherches viennent de disciplines diverses - histoire, ethnologie, sociologie et histoire des religions - qui travaillent avec des méthodes, des présupposés ou des objectifs pouvant diverger de façon importante. L'aspect multidisciplinaire se révèle alors très stimulant et créateur, mais il se trouve également à l'origine de certaines impasses conceptuelles. Les discussions sont ponctuées de nombreuses polémiques, mais les différents chercheurs s'entendent sur un point : la richesse et la complexité des acceptions englobées par l'expression " religion populaire ».

Dès le départ, la question de la définition de la notion retient l'attention des chercheurs. De façon implicite, l'appellation « religion populaire » laisse entendre que cette religion n'est jamais conçue de manière autonome mais plutôt qu'elle existe de façon complémentaire à une autre entité. ${ }^{3}$ Si l'on tente de résumer les diverses approches

2. La documentation est extrêmement abondante et nous ne pouvons citer ici que quelques travaux : Bernard PLONGERON (dir.), La religion populaire . Approches historiques, Paris, Beauchesne, 1976, 237p. ; Guy DUBOSCQ et al., La religion populaire, Colloque international du CNRS en 1977, Paris, Éditions du Centre national de la recherche scientifique, 1979, 449p. ; Carlo PRANDI, "La religion populaire : problèmes théoriques ", The Annual Review of the Social Sciences of Religion, 4 (1980) p. 31-60 ; Franco BOLGIANI, " Religione popolare ", Augustinianum, 3 (1981) p. 7-75 ; Vittorio LANTERNARI, "La religion populaire. Perspective historique et anthropologique ", Archives de sciences sociales des religions, 53 (1982) p. 121-143 ; Benoît LACROIX et Jean SIMARD (dir.), Religion populaire, religion de clercs? , Québec, Institut québécois de recherche sur la culture, 1984, 444p.; Michel LAUWERS, "Religion populaire ", dans Catholicisme. Hier, aujourd'hui, demain, tome 12, Paris, Letouzey et Ané, 1990, p. 835-849.

3. La question d'une autonomie de la religion populaire était sans conteste au coeur du débat lors du colloque international du Centre national de la recherche scientifique à Paris en 1977 ; voir notamment les commentaires lors de la Table ronde dans G. DUBOSCQ et al., op. cit., p. 402. 
et catégories utilisées par les différents auteurs qui se sont intéressés à la question de la définition, on peut dire que la religion populaire est le plus souvent analysée en relation avec les trois lignes directrices suivantes : 1) la religion officielle, cléricale et savante, 2) le folklore, le paganisme et les superstitions, 3 ) les conditions sociales. Chacun de ces points mériterait de longs développements, mais dans le cadre de cet article, seule la deuxième dimension sera ici explicitée : la place, l'importance et le sens à accorder à la superstition dans la composition ou la nature de la religion populaire.

Pour certains chercheurs, la spécificité de la religion populaire se définit par la présence de pratiques et de mentalités que l’Église condamnait en tant que superstition, paganisme ou magie. Ces termes comportent un dénominateur commun : ils font intervenir comme essentiel à la religion populaire un élément structural complémentaire qui n'est pas d'origine chrétienne. Cette idée suggère que, dans sa structure même, la religion populaire ne peut pas se définir seulement par son élément chrétien, pour aussi important qu'on veuille bien le considérer. Elle est structurellement " autre " que le christianisme officiel. L'importance et la place accordées à cet autre élément varie, mais il est toujours présent.

Pour situer les difficultés liés à cette thématique, quelques remarques méthodologiques s'imposent : 1) Les auteurs contemporains qui utilisent le terme de superstition dans le contexte des discussions au sujet du " populaire » spécifient rarement ce qu'ils entendent par cette notion et ils n'expliquent pas souvent à quel type de pratiques ou de croyances ils font référence. Pourtant, les connotations liées à ce terme sont loin d'être claires et, surtout, il est peu probable qu'elles aient eu le même sens pendant toute la période médiévale. 2) Le terme de superstition porte un héritage lourd de significations diverses. D'où l'importance, pour comprendre le sens du mot superstition pendant la période médiévale, de présenter l'évolution de la notion en la replaçant dans une perspective historique. 3) Pour analyser les mentalités populaires, il faut paradoxalement mais inévitablement passer par le discours écrit et savant de l'époque, en l'occurrence celui des clercs. C'est seulement ensuite qu'il sera possible de présenter en guise de conclusion le sens et l'importance des pratiques superstitieuses dans les mentalités populaires.

Notre objectif est donc de présenter et d'analyser la façon dont la notion de superstition a été définie pendant le Moyen Âge afin d'observer son évolution au cours de cette période. Il ne s'agit pas ici 
de procéder à une étude en profondeur de la superstition pendant les mille années de l'histoire médiévale. Cette tâche serait tout à fait disproportionnée et hors sujet. Le propos est plus modeste : se servir de travaux récents pour faire ressortir quelques traits fondamentaux de la perception et de la définition des superstitions par les auteurs du Moyen Âge. Cette étape permettra également de faire ressortir quelques unes des valeurs accolées au terme superstition, valeurs qui ont traversé les siècles et qui se sont répercutées jusque dans les travaux de chercheurs de la deuxième moitié du $\mathrm{XX}^{\mathrm{e}}$ siècle.

\section{Enquête au sujet de la superstition}

Dans l'introduction d'une étude sur les superstitions, Jean-Claude Schmitt fait remarquer que déjà à l'époque romaine le mot superstitio a pris un sens défavorable. Il est opposé à religio qui désigne le scrupule religieux et le souci d'accomplir les rituels selon les règles. " $\mathrm{La}$ superstitio est donc conçue comme une forme pervertie de la religio, souvent entachée d'exagération suivant cet autre sens du préfixe super- : ce qui est superflu (super-fluus), vain, rajouté (super-institus, super-additus ), ou même étranger. ${ }^{4}$ "Selon Schmitt, le christianisme hérita de ces conceptions et la notion de superstition s'identifia à une valeur négative puisqu'elle n'était, pour les auteurs chrétiens, que le paganisme se survivant à l'intérieur du christianisme.

Saint Augustin est le grand théoricien des superstitions et ce qu'il a écrit à ce sujet a pesé sur la tradition chrétienne pendant plusieurs siècles. Deux idées sont particulièrement importantes dans sa façon de les concevoir. La première est que les superstitions sont les survivances de croyances et de pratiques que la mise en place du christianisme a en principe abolies. Ces survivances du paganisme font référence, dans la plupart des cas, à ce que les auteurs chrétiens appellent généralement "idolâtrie ». Ce mot, au-delà du culte des idoles proprement dites, désigne " l'adoration de la créature, qu'il s'agisse de l'homme, du diable, d'un élément de la nature ou d'un objet fabriqué. 5 " L'autre idée

4. Jean-Claude SCHMITT, "Les "superstitions" », dans, Jacques LE GOFF et René RÉMOND (dir.), Histoire de la France religieuse, tome I, Des dieux de la Gaule à la papauté d'Avignon, Paris, Éditions du Seuil, 1988, p. 425.

5. Ibid., p. 429. 
fondamentale chez saint Augustin, c'est l'association qu'il établit entre superstition et démonologie.

L'Église chercha donc dès le début à refouler les superstitions parce qu'elle voyait en elles des survivances du paganisme et la preuve de l'emprise du diable sur l'esprit des hommes. Schmitt souligne cependant que les conditions sociales de l'établissement et de la diffusion du christianisme ont également beaucoup pesé, pendant tout le haut Moyen Âge, sur la manière dont les hommes d'Église perçurent et luttèrent contre les superstitions. ${ }^{6}$ La fusion de la hiérarchie ecclésiastique et de l'aristocratie foncière gallo-romaine, qui se produit aux $\mathrm{IV}^{\mathrm{e}}-\mathrm{V}^{\mathrm{e}}$ siècles, a renforcé l'opposition entre ces milieux privilégiés et l'ensemble du peuple. Il rappelle les polarités idéologiques que traduisent les mots urbani et rustici, de même que l'évolution du mot paganus qui, en français, a donné à la fois les termes "paysan » et " paien ». Cette association entre superstitions et monde paysan sera reprise à travers les siècles. ${ }^{7}$

La notion de " pacte avec le diable » est déjà présente, à sa façon, chez Augustin mais c'est l'âge scolastique qui la précise et la modifie en substituant aux démons la figure du diable. Entre le $\mathrm{X}^{\mathrm{e}}$ et le XIII ${ }^{\mathrm{e}}$ siècle, les mutations des structures économiques et sociales créent de nouveaux pôles à l'intérieur de la culture médiévale et amènent une évolution dans la perception des superstitions par le clergé. ${ }^{8}$ Les développements techniques, le défrichement de nouveaux espaces, la croissance démographique sont tous des facteurs qui contribuent au renouveau des échanges commerciaux, à la naissance des villages et à la renaissance des villes. ${ }^{9}$ Ces transformations sociales, culturelles et idéologiques ébranlent la puissance traditionnelle de l'Église.

Affaiblie par l'ensemble des mutations du temps, l'Église ne pouvait maintenir sa position dans la société qu'en s'infiltrant dans ces cellules nouvelles, en particulier dans les villes. Pour la première fois de son histoire, elle s'intéressa vraiment aux laïcs ; il n'était plus possible de voir

6. Ibid., p. 441.

7. Ibid., p. 442

8. Mais l'attitude de celui-ci ne fut pas tout d'une pièce et il faut distinguer selon les époques et selon les catégories qui le composent. Pour des détails sur les milieux cléricaux concernés, voir Ibid. p. 502-504.

9. Ibid., p. 499-500. 
seulement en eux une masse informe, inculte et «illettrée »; il fallut adapter le langage de l'Église à chaque groupe particulier, à chaque status /.../. En matière de "superstitions ", les clercs firent ainsi des découvertes insoupçonnées. Dans les filets de leurs visites pastorales, de leurs tournées de prédication ou de leurs inquisitions, ils ramenèrent une masse d'informations d'une richesse sans précédent sur des légendes, des croyances, des rituels. ${ }^{10}$

$\mathrm{Au} \mathrm{XIII}$ e siècle, l'équilibre entre la curiosité « ethnologique » et la visée répressive est rompue. La création des Ordres mendiants et la spécificité de leur mandat amorcent un tournant dans ce sens. "Les superstitions paysannes sont devenues incompréhensibles à ces religieux formés et vivant en ville et ne pensant plus que dans les catégories bien tranchées du droit canon ou de la théologie scolastique. ${ }^{11}$ »

Le rôle joué par saint Thomas d'Aquin fut décisif dans la définition de la théorie de superstition. Saint Thomas s'inspire largement de saint Augustin, mais il a une conception plus restrictive de la superstition et il porte un jugement plus dur envers ceux qui s'en rendent coupables. Celui qui a passé un "pacte exprès » avec le diable n'est pas coupable par ignorance ou simplicité mais plutôt parce qu'il est un complice actif de Satan. Le "thomisme a donc fait faire un pas considérable aux attitudes répressives à l'égard des "superstitions", ou du moins des plus graves d'entre elles. Le concept clérical de sorcellerie, tel que la "chasse aux sorcières" le mettra très concrètement en œuvre à la fin du Moyen Âge, trouve ici un des ses points d'ancrage théorique. ${ }^{12}$ »

C'est aussi pour d'autres raisons que le XIII ${ }^{\mathrm{e}}$ siècle marque une étape dans la perception des superstitions. D'abord, le durcissement des positions théologiques de la hiérarchie ecclésiastique trouve un écho dans l'intensification de la lutte contre ces pratiques. Mais surtout, l'époque connaît une modification dans la façon de les concevoir. Le regard des clercs change et les superstitions, malgré une apparente immobilité, ne sont plus toujours les mêmes. Différents facteurs - les transformations de la société, les conditions d'encadrement des fidèles, les succès de la christianisation — lient plus étroite-

10. Ibid., p. 502.

11. Ibid., p. 504.

12. Ibid., p. 505-506. 
ment que par le passé les superstitions aux formes officielles du culte chrétien. ${ }^{13}$ Elles sont davantage perçues comme un détournement des pratiques légitimes par les autorités ecclésiastiques.

Il n'était plus question, aux XIII ${ }^{\mathrm{e}}$ et $\mathrm{XIV}^{\mathrm{e}}$ siècles, de condamner comme dans le passé les "survivances " les plus outrancières du paganisme antique ; désormais, c'est au sein même des pratiques légitimes qu'il fallait traquer les "superstitions ", dans l'espace de l'église et du cimetière, dans la pratique des sacrements, ou encore à la limite, souvent transgressée par les laïcs, d'un domaine du sacré que les prêtres entendaient se réserver. ${ }^{14}$

Les pratiques considérées comme superstitieuses pendant ces deux siècles concernent les fêtes populaires et religieuses, le cimetière, l'église, l'hostie, le saint-chrême, le culte des saints et des images. Deux dynamiques peuvent être observées à travers ces différents cas. D’une part, "la concurrence acharnée que se livrent la culture de l'Église et la culture folklorique pour le contrôle des lieux sacrés et notamment de l'espace des morts ", ${ }^{15}$ et d'autre part, la transformation de plusieurs formes du culte divin qui modifie de manière sensible les rapports entre le licite et l'illicite ou entre la religion et la superstition. ${ }^{16}$ Pendant la même période, les clercs s'occupent aussi de traditions qui ne peuvent pas être assimilées aux pratiques légitimes et qui concernent le culte des morts. ${ }^{17}$

Schmitt situe l'évolution de la notion de superstition pendant le bas Moyen Âge en relation avec la sorcellerie et la culture urbaine. Il cite différentes mentions de sorcellerie dans les textes cléricaux entre les $\mathrm{XII}^{\mathrm{e}}$ et XIII ${ }^{\mathrm{e}}$ siècles qui relatent des exemples de sorts jetés aux gens ou aux bêtes. "Les sorts permettaient d'expliquer toutes les formes du "malheur biologique" ; la maladie, la mort et, surtout, l'impuis-

13. Ibid., p. 506-507.

14. Ibid., p. 510. Un auteur qui a travaillé sur la magie au Moyen Âge remarque la même transformation de la notion de superstition à cette époque, un phénomène qu'il place en relation avec la préoccupation du clergé quant à l'existence possible d'une magie diabolique. Voir Richard KIECKHEFER, Magic in the Middle Ages, Cambridge, Cambridge University Press, 1989, p. $184-185$.

15. J.-C. SCHMITT, «Les "superstitions" ", p. 511.

16. Ibid., p. 513.

17. Ibid., p. 524-533. 
sance sexuelle.» ${ }^{18}$ À travers les récits de maleficium, ce n'est pas l'existence de telles pratiques de sorcellerie paysanne au XIII ${ }^{\mathrm{e}}$ siècle que Schmitt veut faire ressortir, puisqu'elles sont aussi attestées dans des textes du haut Moyen Âge, mais plutôt la différence qui s'accentue entre les conceptions cléricales et ces textes.

Ce qui est relativement nouveau à partir du $\mathrm{XIII}^{\mathrm{e}}$ siècle, et qui se révélera déterminant pour les siècles suivants, c'est l'association de plus en plus fréquente, de la part du clergé, entre les sorts (le maleficium ) et la question d'un pacte conclu avec le diable. À partir de ce moment, le fossé se creuse entre la conception cléricale de la sorcellerie et celle pratiquée par la société rurale.

Certains des facteurs qui ont influencé les conceptions cléricales relèvent de la situation de l'Église au XIII ${ }^{\mathrm{e}}$ siècle qui se sent menacée par le développement d'hérésies populaires, notamment celles des vaudois et des cathares. En 1258-1260, les membres de l'Inquisition, le tribunal créé pour combattre ces hérésies, reçoivent l'ordre de s'intéresser aussi aux superstitions, sortilèges et divinations ayant saveur d'hérésie. Il s'agit là d'un tournant important dans la façon de percevoir les superstitions et cette hantise cléricale des menées diaboliques se continue au $\mathrm{XIV}^{\mathrm{e}}$ siècle et elle s'amplifie à partir du XV siècle.

La culture urbaine, qui s'est développée à partir des $\mathrm{XI}^{\mathrm{e}}-\mathrm{XII}{ }^{\mathrm{e}}$ siècles, a ouvert un autre front pour l'Église dans sa lutte contre les superstitions. "Pour bien des raisons, cette culture urbaine était une culture paysanne urbanisée. Mais, en ville, tout était différent : l'organisation d'un espace plus dense et fermé, une scansion plus forte du temps, une plus grande diversité des groupes sociaux et des formes de sociabilité par lesquelles chacun d'eux affirmait son identité. ${ }^{19}$ " Schmitt observe quelques transformations et adaptations dictées par le contexte urbain, à travers les rituels de la fête des fous, du carnaval, et du charivari. Mais il montre aussi que la lutte contre les superstitions y prend une autre connotation. Leur condamnation ne vise plus seulement à sauvegarder l'authenticité de la foi ou la conformité des comportements religieux par rapport à la norme cléricale, mais il s'agit tout autant de marquer la supériorité de la ville sur la campagne en

18. Ibid., p. 535.

19. Ibid., p. 543. 
portant un jugement culturel qui s'exprime par la dérision et l'anathème. ${ }^{20}$ Dans le cadre de la culture urbaine, les superstitions perdent leur statut proprement religieux, en ce sens que progressivement elles sont davantage associées à l'obscurantisme populaire et rural qu'au paganisme. «Elles trahissaient une carence culturelle et non plus un manque de foi. ${ }^{21}$ »

On peut donc résumer ainsi les deux tendances majeures mises en relief pour la fin du Moyen Âge : 1) L'association de plus en plus fréquente, à partir du XIII ${ }^{\mathrm{e}}$ siècle, dans l'esprit des clercs et des théologiens, entre les pratiques de sorcellerie et la notion de pacte diabolique. 2) La perte du statut religieux des superstitions dans le contexte urbain.

\section{Valeurs accolées à la superstition}

Trois autres chercheurs mettent en lumière la transformation des valeurs accolées au terme "superstition » pendant le Moyen Âge.

Jean-Claude Bologne résume de la façon suivante le parcours de la superstition et de la magie perçues par les clercs au Moyen Âge : idolâtrie, superstition, invocation des démons. L'auteur se sert du jugement de l'université de Paris sur Jeanne d'Arc pour illustrer cette évolution.

Idolâtre? C'est le stade du haut Moyen Âge, lorsqu'il fallait encore lutter contre le paganisme et que tout acte à relents animistes semblait un culte rendu à d'anciens dieux. Superstitieuse? C'est l'attitude des XII ${ }^{\mathrm{e}}-\mathrm{XIII}{ }^{\mathrm{e}}$ siècles, lorsque le paganisme semble vaincu et que les croyances paysannes inspirent plutôt le sourire ou la pitié. Invocatrice de démons? C'est la hantise du $\mathrm{XV}^{\mathrm{e}}$ siècle, quand on verra le diable derrière toutes les manifestations surnaturelles. De magicienne antique à paysanne crédule, Jeanne est devenue sorcière. ${ }^{22}$

Il indique que le même schéma pourrait s'appliquer à plusieurs autres thèmes. ${ }^{23}$ Les trois périodes qu'il dégage correspondent, selon

20. Schmitt cite à l'appui des textes littéraires comme le Roman de Fauvel, le Jeu de la Fenillée ou les Évangiles des Quenouilles.

21. Ibid., p. 551.

22. Jean-Claude BOLOGNE, Du flambeau au bûcher. Magie et superstition au Moyen Âge, Paris, Plon, 1993, p. 84. 
lui, à trois mouvements qui se recouvrent, mais aussi qui dominent à certains moments de l'histoire médiévale.

Un mouvement d'assimilation, un mouvement de folklorisation, un mouvement d'exclusion. Leur succession suit l'élimination progressive de la culture païenne : à un premier stade, on tâche de la fondre dans une culture commune ; à un second, on la tolère à un niveau inférieur de la connaissance du monde (culture savante, culture populaire); à un troisième, on la nie en tant que culture propre et on en fait une contreculture, diabolique et non-divine. ${ }^{24}$

Mary O'Neil, de son côté, propose une vue d'ensemble de l'application historique du terme superstition. Tenant compte du fait que les significations accolées à ce terme ont varié énormément selon les périodes et les contextes, cette approche lui semble la meilleure et préférable à une définition abstraite. En ce qui concerne la période médiévale, ses remarques rejoignent et complètent celles des auteurs cités précédemment. L'Église primitive hérite de la perception des Romains pour qui la superstition est définie en relation avec des conduites religieuses fausses, erronées ou excessives qui proviennent de l'ignorance du peuple ordinaire (vulgus) et de celui des campagnes (pagus). La condamnation des superstitions concerne aussi les pratiques d'idolâtrie. "This use of superstitio to categorize the whole of classical pagan religion as idolatrous and even demonic constitutes a basic core of meaning that persists throughout the Christian era. " Pendant le haut Moyen Âge, la question des superstitions est perçue comme un combat contre les survivances du paganisme. Puis, à partir de la période scolastique, avec saint Thomas d'Aquin, on classifie en général les pratiques idolâtres, la divination et les pratiques magiques en tant que superstitions. "The Scholastic theory of the diabolical pact as the causative mechanism behind magical effects assured that superstition in its medieval version was perceived as neither "harmless" nor inefficacious. " Dans le contexte du développement des hérésies et des débuts de l'Inquisition, le XIII ${ }^{\mathrm{e}}$ siècle marque un point tournant dans l'attitude envers les pratiques magiques, parce que, progressivement, la juridiction inquisitoriale commence à s'occuper

23. «/.../ les croyances, fragmentées après la dislocation des cultes païens (culte des morts, cultes de la nature, personnification du destin...), persistent sous forme de superstitions tenaces. " Ibid., p. 91.

24. Ibid., p. 280-281. 
aussi des cas de superstition possiblement teintée de satanisme. «By the fifteenth century, however, the theory of the implicitly diabolical pact was invoked to extend inquisitorial jurisdiction to the magical activities of the illiterate population. ${ }^{25}$ » Notons que l'auteure parle de pratiques magiques et superstitieuses sans les définir ou faire des distinctions entre elles.

Pierre Boglioni, pour sa part, note qu'entre les $\mathrm{V}^{\mathrm{e}}$ et $\mathrm{XV}^{\mathrm{e}}$ siècles une série de textes théologiques, pastoraux et juridiques montrent la préoccupation constante de l'Église d'extirper des pratiques religieuses alternatives qui sont désignées principalement sous le terme de superstitiones. Il remarque la difficulté de traduire le mot superstition dans le langage moderne et de lui conserver les nuances que lui attribuent les auteurs médiévaux. ${ }^{26}$ Une analyse des textes médiévaux concernant la superstitio montre que le sens du terme se trouve en équilibre instable entre trois dimensions divergentes, bien que complémentaires. Pour chacune de ces dimensions, l'auteur cite les qualificatifs utilisés dans les textes médiévaux. La première dimension, d'ordre historique, rattache la superstition à la culture religieuse préchrétienne en tant que vestige du paganisme; la deuxième, d'ordre culturel ou social, interprète la superstition comme des sottises qui sont le fait d'ignorants ou bien elle l'associe à la notion d'infériorité sociale et de marginalité ; la troisième, d'ordre théologique, interprète la superstition comme une invention de Satan et son instrument de domination sur les hommes. ${ }^{27}$

Ces différentes dimensions ne sont ni étanches ni exclusives entre elles et leur importance respective se transforme au cours de la période médiévale. Entre les $\mathrm{VI}^{\mathrm{e}}$ et $\mathrm{XI}^{\mathrm{e}}$ siècle, la dimension historique prédomine et les phénomènes décrits comme superstitions sont désignés comme des persistances du paganisme. Puis entre le XII et le $\mathrm{XIV}^{\mathrm{e}}$ siècle, dans le contexte du développement des hérésies, l'ennemi principal

25. M. O'NEIL, "Superstition" in Mircea Eliade (éd.), The Encyclopaedia of Religion, 1987, vol. 14, p. 164.

26. Pierre BOGLIONI, "Le sopravvivenze pagane nel medioevo », in Peter Slater et al. (éds), Traditions in Contact and Change. Selected Proceedings of the XIVth Congress of the International Association for the History of Religions, Waterloo, Wilfrid Laurier Press, 1983, p. 349.

27. Ibid., p. 350. 
de l'Église n'est plus l'héritage du passé, mais plutôt ces nouvelles forces qui contestent ses structures et les bases de son pouvoir. On assiste également à une folklorisation de la superstition. La culture ancestrale recule avec l'urbanisation et, grâce au renfort apporté par les ordres mendiants dans l'encadrement des fidèles, l'Église croit que le poids des superstitions s'est affaibli et qu'elles peuvent dorénavant être considérées comme des curiosités inoffensives et d'intérêt mineur. Enfin, à partir du début du $\mathrm{XV}^{\mathrm{e}}$ siècle, l'explication théologique de la superstition comme le résultat de l'œuvre satanique et son identification avec la sorcellerie efface les anciennes interprétations. La sorcellerie apparaît aux théologiens non comme un vestige du passé, mais comme une anti-religion contemporaine. Tout à coup, des éléments folkloriques épars et incohérents sont promus à la dignité d'une nouvelle religion et sont reliés non à des racines historiques ou locales, mais à une antiéglise universelle. Dans l'explication de la superstition, la théologie se substitue entièrement à l'histoire et à la sociologie. ${ }^{28}$

À ces trois grandes périodes $\left(\mathrm{VI}^{\mathrm{e}}-\mathrm{XI}^{\mathrm{e}} \mathrm{S}\right.$., $\mathrm{XII}^{\mathrm{e}}-\mathrm{XIV}^{\mathrm{e}} \mathrm{S}$., Début $\mathrm{XV}^{\mathrm{e}} \mathrm{S}$.) de la thématique médiévale de la superstition correspondent des situations documentaires diverses et différents problèmes méthodologiques. Dans la première phase, le matériel est abondant, direct, mais la limite de cette documentation réside dans le fait qu'elle représente uniquement le point de vue de l'Église et qu'elle montre une nette tendance à la répétition. Ainsi les textes peuvent mentionner comme encore vivantes des pratiques déjà déclinantes ou transposer d'une région à une autre des phénomènes comparables. Malgré la grande quantité de documents et l'apparente abondance de détails dans les textes du haut Moyen Âge, la religion concrète du petit peuple nous échappe, plus encore que pour toute autre période. Du XII au $\mathrm{XIV}^{\mathrm{e}}$ siècle, le matériel devient plus fragmentaire, plus difficile à repérer et les informations concernent davantage la discussion théorique des lettrés que l'expérience directe. Cependant, la culture laïque commence à laisser filtrer un contenu qui lui est propre, soit dans la production de langue vulgaire, soit à travers divers filons qui pénètrent la culture ecclésiastique (exempla, art, légendes). Puis au $\mathrm{XV}^{\mathrm{e}}$ siècle la documentation redevient abondante avec différents textes portant explicitement sur les superstitions. Les manuels des Inquisi-

28. Ibid., p. 351. 
teurs s'en occupent également et, en rapportant les propos du peuple, ils fournissent une documentation d'un nouveau type. Dans ce type de sources, désormais, la problématique de la superstition est devenue presque exclusivement celle de la sorcellerie, mais, dans la conscience des inquisiteurs, le rapport entre celle-ci et le monde païen du passé a tout à fait disparu. ${ }^{29}$

\section{Les superstitions dans les mentalités populaires}

Maintenant que nous avons vu comment les autorités médiévales perçoivent et définissent les superstitions, nous aimerions mettre en valeur le sens et l'importance des pratiques superstitieuses dans les mentalités populaires.

En effet, l'une des questions qui se situent au cœur de la définition de la religion populaire concerne la présence d'un système de croyances et de pratiques qui, loin d'être marginales et irrationnelles, feraient en fait partie d'une conception cohérente du monde. L'idée revient chez plusieurs auteurs pour expliquer le sens, la fonction et l'importance de la superstition et de la magie dans les conceptions populaires. Selon eux, plutôt que de se demander si une pratique est magique, superstitieuse ou populaire, il faut chercher ce qu'elle représente et la signification qu'elle recèle.

Les discussions entre l'historien Keith Thomas et l'anthropologue Hildred Geertz illustrent ce propos. ${ }^{30}$ Pour résumer l'essentiel du débat, disons que Geertz reproche à Thomas de ne pas avoir perçu le sens et la fonction véritables des pratiques magiques dans les mentalités populaires. ${ }^{31}$ Thomas, en décrivant les rituels magiques en tant que simples réponses à des besoins matériels immédiats, aurait négligé de tenir compte du fait que ces pratiques reposaient sur des fondements conceptuels qui constituent une cosmologie cohérente. Les croyances magiques, selon Geertz, possèdent une existence qui leur est propre tandis que Thomas les aurait décrites simplement en termes

29. Ibid., p. 351-352.

30. "An anthropology of Religion and Magic. Two views ", Journal of Interdisciplinary History, 6 (1975) p. 71-109. Cette discussion fait suite à la publication du livre de K. THOMAS, Religion and the Decline of Magic, New York, Charles Scribner's Sons, 1971, 716p.

31. H. GEERTZ, op. cit., p. 86-87. 
utilitaires, ce qui impliquerait que ces croyances naissent pour répondre à des besoins pratiques et qu'elles sont écartées lorsque ceux-ci disparaissent.

En réponse à Geertz, Thomas rappelle qu'il avait suggéré que les rituels magiques pouvaient parfois contenir des aspects chargés de sens, mais il réaffirme que leurs objectifs étaient habituellement strictement d'ordre pratique. Si les médecins, la police ou l'Église avaient été en mesure de répondre aux besoins des gens, ceux-ci n'auraient pas eu recours aux magiciens en tous genres. "Counter-witchcraft, magical healing, exorcism, were not just expressive or symbolic rites : they were meant to work. ${ }^{32}$ "

Thomas rappelle également que les anthropologues sont loin de s'entendre sur le degré de cohérence qu'un chercheur peut s'attendre à trouver dans l'étude des croyances d'un peuple et que les schémas développés par certains sont considérés par d'autres comme bien audelà des évidences fournies par les données ethnographiques.

Selon Thomas, ce que le chercheur rencontre pour la période étudiée ne consiste pas en un code unique mais plutôt en un amalgame de débris culturels de différentes façons de penser, tant chrétiennes que païennes, germaniques ou classiques, et il serait absurde de prétendre que ces éléments ont été réorganisés en un système nouveau et cohérent. $^{33}$

Même si Thomas reconnaît qu'une plus grande place doit être accordée à l'aspect symbolique du magique populaire, il insiste pour dire qu'il reste à établir si ces rituels constituaient toujours un système cohérent ou bien si, comme l'implique l'ancienne manière de définir le mot superstition dans le sens de survivance, ils représentaient seulement des vestiges inorganisés d'anciens modèles conceptuels. ${ }^{34}$

Le débat repose peut-être sur un problème de sémantique, en ce sens que les diverses définitions par lesquelles les théologiens, les historiens et même jusqu'à tout récemment les anthropologues qui ont

32. K. THOMAS, « An Anthropology of Religion and Magic, II », p. 101.

33. Ibid., p. 104.

34. Ibid., p 106-107. 
essayé d'atteindre les différents systèmes ou pratiques, sont en fait un produit des débuts de la période moderne. ${ }^{35}$ Les distinctions entre superstition, magie et religion ont été énoncées par les réformateurs du XVI ${ }^{\mathrm{e}}$ siècle dans le but d'attaquer les éléments de la religion médiévale qu'ils n'acceptaient pas, mais ces catégories seraient inadéquates pour illustrer les réalités de la période qui précède la Réforme. ${ }^{36}$

Pour les chercheurs qui se sont intéressés aux phénomènes religieux populaires, la question de savoir si les pratiques superstitieuses et magiques forment un ensemble de croyances ou bien si, au contraire, il s'agit de notions éparses ayant une fonction ponctuelle est importante parce qu'elle concerne le "statut " de la religion populaire : faut-il considérer celle-ci comme un ersatz de la religion officielle ou bien représente-t-elle une véritable " religion alternative »? La réponse est reliée à la notion de culture folklorique et à l'importance qu'il faut lui accorder dans la définition de la religion populaire.

Jean-Claude Schmitt et Jacques Le Goff ont été les premiers à utiliser la notion de culture folklorique — le terme « culture » soulignant la

35. Patrick J. GEARY, « La coercition des saints dans la pratique religieuse médiévale ", dans Pierre BOGLIONI (dir.), La culture populaire au Moyen Âge, Montréal, L'Aurore, 1979, p. 158.

36. Jacques Le Goff et Jean-Claude Schmitt font une remarque similaire en signalant un problème conceptuel et méthodologique présent dans plusieurs études sur les mentalités religieuses ou populaires. "Leur défaut le plus fréquent est d'oublier que sous la continuité apparente du langage, l'histoire a fait son œuvre, et que les notions de "religion", de "sacré", de "magie", de "croyance", comme du reste celles d' "économie" ou de "politique" et bien d'autres encore, ne peuvent s'appliquer telles quelles aux réalités médiévales. En effet, les sens que nous reconnaissons aujourd'hui à ces mots et l'autonomie relative des sphères d'activité que ces mots distinguent dans le champ social, sont largement le produit d'une époque récente, celle des Lumières puis de la société bourgeoise du XIXe siècle, celle du premier développement de la science historique. Mais le travail de médiéviste consiste au contraire à penser autrement les "caractères originaux" d'une époque très différente de la nôtre par son organisation matérielle, sociale, idéologique. » Voir "L'histoire médiévale ", La recherche sur le Moyen Âge à l'aube du vingt-et-unième siècle, Cahiers de civilisation médiévale, 39 (1996) p. 16. 
cohérence du système social - comme élément dialectique essentiel dans la définition de la religion populaire et de sa dynamique.

Pour Jean-Claude Schmitt, la religion populaire ne peut être dissociée de la culture folklorique qui sous-tend le quotidien et l'essentiel de la vie religieuse des masses : leurs croyances, leurs légendes, leurs attitudes à l'égard de leurs parents, de leurs morts, etc. ${ }^{37} \mathrm{Il}$ s'interroge sur le sens à donner à « religion » et sur la place de celleci dans la culture folklorique. Dans le contexte de la société médiévale, où les rapports des hommes entre eux et avec la nature étaient particulièrement étroits, la religion, en tant que "système symbolique d'interprétation du monde et d'action symbolique sur lui, avait un champ d'extension extrêmement vaste : elle informait l'ensemble des représentations que les hommes avaient de leurs activités. ${ }^{38}$ " La progression du christianisme ne pouvait se réaliser sans rencontrer la culture folklorique. ${ }^{39}$ C'est pourquoi le problème de la religion populaire doit être posé à travers les relations de la culture cléricale et de la culture folklorique dont il faut chercher à comprendre les significations et les enjeux. ${ }^{40}$

Il apparaît du moins que la christianisation, et par conséquent aussi les contacts entre culture cléricale et culture folklorique sous l'une ou sous l'autre forme, se sont intensifiés aux époques de transformation du corps social, c'est-à-dire précisément quand le rôle et la position dominante de l'Église risquaient d'être brutalement mis en cause. La collecte de récits folkloriques au tournant des $\mathrm{XII}^{\mathrm{e}}$-XIII ${ }^{\mathrm{e}}$ siècles par les auteurs d'exempla, les débuts de la chasse aux sorcières au tournant des $\mathrm{XI}^{\mathrm{e}}$ $\mathrm{XV}^{\mathrm{e}}$ siècles, doivent être analysés dans ces perspectives. ${ }^{41}$

L'histoire des superstitions et de la magie rencontre celle de la culture populaire et du folklore. Pendant longtemps « la prise en compte du seul point de vue de la culture officielle a empêché de comprendre les logiques propres de la culture du menu peuple et réduit par exemple la "religion populaire" à une forme dégradée de la religion des

37. J.-C. SCHMITT, "Religion populaire » et "culture folklorique ", Annales ESC, 31 (1976) p. 944.

38. Ibid., p. 945.

39. Ibid., p. 947.

40. Ibid., p.947 et 940 .

41. Ibid., p. 948. 
élites. $^{42}$ » On retrouve ici un trait caractéristique de la culture folklorique qui a été proposé par Jacques Le Goff : les pratiques superstitieuses doivent aussi être analysées comme l'expression d'une logique particulière.

Schmitt, pour sa part, met en valeur le principe méthodologique important qui consiste à tenir compte de la dialectique entre conception cléricale et culture folklorique pour comprendre l'évolution du sens accolé au mot superstition.

Tout en traitant des "superstitions ", donc en partant du discours de l'autorité, de l'ordre et de la contrainte, il faudra essayer de tenir ensemble les « deux bouts » de la réalité historique, pour montrer comment le jugement porté sur les "superstitions " pouvait traduire des décalages, des incompatibilités ou des incompréhensions culturelles ; pour monter aussi que, sur la ligne de front fluctuante que les usages du mot " superstition » dessinent à travers les siècles, l'assaut n'est jamais venu d'un côté seulement : la pression des « superstitions » a toujours entretenu avec la loi et l'autorité un rapport dialectique dont le produit historique, qu'on nomme l'histoire religieuse, est un enchevêtrement et une succession de figures de compromis. ${ }^{43}$

Schmitt rappelle aussi la nécessité d'étudier cette notion par rapport à la fonction et à la signification de comportements superstitieux pour ceux qui les intègrent. «Il est donc nécessaire d'essayer d'inverser notre point de vue, de privilégier ce qui semblait au contraire essentiel à la masse des fidèles et pouvait justifier son attachement durable aux conduites ou aux représentations incriminées. ${ }^{44}$ » Les besoins des hommes de l'époque s'expriment principalement dans les trois domaines suivants :

D'abord, dans une civilisation agraire et à la merci des forces de la nature, le souci d'assurer la fertilité, la fécondité, la reproduction des hommes, des bêtes et des fruits de la terre. Ensuite, la maîtrise symbolique de l'espace, pour favoriser justement cette emprise de l'homme sur son environnement et pour inscrire dans l'espace social la succession des générations ; le culte des morts et ses lieux spécifiques devinrent ainsi un enjeu important du conflit entre l'Église et les «superstitions ». Essen-

42. J-C. Schmitt, « Les “superstitions” », p. 422.

43. Ibid., p. 423.

44. Ibid., p. 453. 
tiels, enfin, sont la connaissance et si possible le contrôle du temps, du temps qu'il fait et qui risque de ruiner les récoltes, et du temps futur que les présages, peut-être, permettront de deviner. ${ }^{45}$

Ces différents domaines recoupent donc des angoisses séculaires dans l'histoire de l'humanité. Elles tournent autour de thèmes liés à la vie, à la mort, à l'amour, au futur et à la nature. Que ces pratiques fassent partie d'un système qui offre une lecture du monde ou qu'elles puissent simplement jouer un rôle ponctuel, le débat reste ouvert entre chercheurs. Mais à notre avis, l'un des apports essentiels des études qui définissent la spécificité de la religion populaire en relation avec la présence de pratiques superstitieuses et magiques est d'avoir montré l'importance d'étudier ces pratiques non seulement en fonction de l'orthodoxie qui les combat mais aussi comme interprètes de rôles culturels et religieux originaux.

\section{RÉSUMÉ}

La superstition, toujours difficile à cerner, est une forme de religion populaire plus ou moins reçue ou tolérée. Durant la longue période du Moyen Âge, elle prend différentes figures dont on ne peut rendre compte facilement. Le propos de cet article est de faire ressortir, à partir de travaux récents, quelques traits fondamentaux de superstitions au Moyen Âge en tenant compte, entre autres, de la perception de certains auteurs de cette période. À la suite de cela, nous pourrons mieux saisir quelques unes des valeurs accolées à ce terme de superstition, valeurs qui ont traversé les siècles et qui se sont répercutées jusque dans les travaux de chercheurs de la deuxième moitié $\mathrm{du} \mathrm{XX}^{\mathrm{e}}$ siècle.

\section{ABSTRACT}

Superstition as a form of popular religion more or less accepted or tolerated is difficult to figure out. During the Middle Ages it undertook different faces not easy to explain. With recent researches and the help of the perception from some Middle Ages authors, this article will put forward traits of that particular period about superstition. Following that we will be able to grasp values that close related to the terms of superstition and have been carry on through centuries, even in researchers'work of the second half of the twentieh century.

45. Idem. 